\title{
A CRITICAL AND STATISTICAL STUDY OF THE DETERMINATION OF SEX, PARTICULARLY IN HUMAN OFFSPRING. ${ }^{1}$
}

\author{
F. H. PIKE.
}

\section{INTRODUCTION.}

Cú́not ('99) and Strasburger (:00) summarized the evidence in favor of the heredity of sex in animals and plants, respectively. Rauber $(: 00)$ in the same year as Strasburger, declared for the heredity of sex in man.

Bateson in 1902 suggested that the Mendelian law might apply to the heredity of sex. Castle (:03), accepting Cuénot's and Strasburger's views without question, formulated an hypothesis to account for the heredity of sex in accordance with Mendel's law. Weldon (:01) had already shown that Mendel's original results with cotyledon color in peas differed from the theoretical numbers by something less than the limits of error. At the time Castle's theory appeared, it occurred to me to gather statistics of births in order to determine in a similar way the probability that the actual numbers of male and female births would be the numbers demanded by the hypothesis.

\section{Review of Previous Work.}

The idea that the sex of the offspring could be influenced by changing the environment of the parents or of the very young embryo has long been current. Yung's ('83) experiments on tadpoles, in which he was apparently able to control the sex by

${ }^{1}$ This study was begun under the direction of Professor C. H. Eigenmann of the Department of Zoology of Indiana University and was completed in the Hull Physiological Laboratory of the University of Chicago. The author desires to express his obligations to the health officers and registrars who have supplied him with statistics; to his colleagues in the Hull Laboratory for criticism of the manuscript; and to Professor Eigenmann for encouragement and assistance. 
changing the nutrition, have been cited as a demonstration of this point. Statistics of human births have been judged in such a way as to lend some support to this view. A good review of this aspect of the question has been given by Geddes and Thompson (:01). The validity of such conclusions has been well discussed by Newcomb (:04), who has made a statistical inquiry into the probable causes of sex in the human subject. Newcomb concludes that the causes of sex are beyond voluntary control.

Cuénot repeated Yung's experiments on tadpoles with contrary results. Eggs from the same mother, but of different layings, gave a more constant proportion of males to females than Yung obtained. The ratio of males to females in the young $(54.85 \%$ females) did not differ materially from the ratio $(61.5 \%$ females $)$ existing among the metamorphosed tadpoles found in a state of nature in the vicinity of Nancy. Born ('81) found 52 per cent of females in the metamorphosed tadpoles near Breslau. Griesheim ('81) found 63.63 per cent of females in young Rana temporaria in the vicinity of Bonn. Pflüger ('81) found 64.5 per cent of females in the same vicinity, and 86.8 per cent near Utrecht. The percentage of old females in the latter vicinity he found to be 51.2. Pflüger concluded that the sex was determined in the egg. From his results on tadpoles and other animals, Cuénot likewise concluded that sex was not influenced by the conditions of development. He decided further that there was a certain sexual ratio common to the frogs of any particular vicinity, and that this ratio might vary among frogs of different localities. In view of the comparatively small number of frogs observed, the last conclusion may possibly be open to question.

Von Malsen (:06) and Issakowitsch (:06), the former for the worm Dinophilis apatris and the latter for Daphnia, have recently reaffirmed the statement that an abundance of food and a low temperature cause a greater number of eggs to develop into females, while a higher temperature and a scarcity of food result in the development of a greater number of males. The food supply, according to them, is the main factor in this process, and the temperature acts only indirectly by influencing the nutrition. It is to be remembered, however, that in experiments dealing with a whole animal, it is difficult to exclude all causes except food and temperature. 
Strasburger (:00) made many experiments with diœcious plants, growing them on various kinds of soil and under various conditions, in the attempt to modify the sexual ratio. The following results with Melandrium album may be cited as an example:

Table I.

\begin{tabular}{lccc}
$\quad$ Kind of soil & Males & Females & $\begin{array}{c}\text { Females } \\
\text { to 100 males. }\end{array}$ \\
Fertilized garden soil & 410 & 562 & 137.0 \\
Unfertilized garden soil & 235 & 282 & 120.0 \\
Fertilized field soil & 384 & 479 & 124.4 \\
Unfertilized field soil & 254 & 307 & 120.8 \\
Sand & 321 & 411 & 128.0 \\
\multicolumn{1}{r}{ Totals } & 1604 & - & - \\
\end{tabular}

Thus sexual ratios for groups of plants grown under the most diverse nutritive conditions did not differ greatly from the mean. Strasburger concluded that an arbitrary determination of sex in dioecious phanerogams has never been accomplished, and he is inclined to apply this conclusion to all plants.

Rauber (:00) studied statistically the distribution of sex in man. He found everywhere an excess of male births, but this early excess in the young was changed, because of the greater mortality of the males, ${ }^{1}$ to an excess of females in later life, and particularly in old age. He showed that the sexual ratio for Europe was 1000 female to 1060 male births, and that this mean ratio was fairly constant in the different parts of Europe. Reasoning on the basis that, if sex was determined by environment, the great diversity of external conditions in the different parts of Europe should cause a considerable difference in the sexual ratios for the different countries, he concluded that sex is hereditary in man.

According to Rauber, there is normally an excess of female births in horses, sheep and certain other domestic animals.

Punnett (:04a) has made a statistical study of the distribution

${ }^{1}$ The relative death rates per million infants of each sex, as determined from Tatham's English Life Tables is 161,036 males and 131,126 females during the first year after birth. The excess of male deaths is 29,910 per million infants of each sex, or approximately 1.57\%. (Cited by Punnett, :04a, p. 265). 
of male and female births in London, in order to determine whether or not the sexual ratio is affected by the nutrition of the parents. For this purpose he divides London society into three groups, following Rowntree's (:02) division of the society of York. These groups are (1) the servant keeping class, (2) the artisan class in which the family earnings are in excess of 26 shillings a week, and (3) the laboring class in which the family earnings fall below 26 shillings a week. Rowntree found that, compared with a standard dietary containing 125 grams of proteid and possessing a total energy content of 3500 calories, the first group has a dietary containing more food than is necessary for the maintenance of health; that the second class has, in general, a sufficient diet, although the family must practice strict economy in order to procure it; the third class is, as a rule, seriously underfed, the average deficiency in proteids amounting to as much as 29 per cent. Assuming that these considerations apply to London as well as to York, Punnett finds that there is either no effect upon the sexual ratio which can be attributed to parental nutrition, or, at most only a very small effect. He finds also that the statement of Düsing as to the greater proportion of males among the first born children is supported by the statistics of the English lying-in hospitals. Furthermore, mothers whose first birth occurs between the ages of nineteen and twenty-three years bear a larger proportion of males at this birth than mothers whose first birth occurs either earlier or later in life.

\section{Statistical Data.}

On the fundamental errors in the statistics.- Rauber (:00) has considered the errors in even the best statistics, and only a brief discussion of them will be given here. In order to compute the exact sexual ratio, it is necessary to obtain statistics of all births, both premature and full term, living or still born. The effect upon the sexual ratio of disregarding the premature and still births will be pointed out below. For purposes of heredity, homologous or duplicate twins, developed from a single ovum, and invariably of the same sex, should be counted as a single birth. The author has at hand no sufficient data upon which to base an idea of the magnitude of the error which might be intro- 
duced by counting such twins as two births. Of the eighteen cases of twins and triplets considered by Wilder (:04), twelve pairs of duplicate twins were females. If such a large proportion of all duplicate twins should be females, the error introduced would be considerable, and the preponderance of male births increased. The number of cases given, however, is too small to warrant drawing conclusions as to the relative frequency of male and female duplicate twins.

The sexual ratio.- The sexual ratios for eleven European countries, as they existed sometime during the latter part of the nineteenth century, have been taken from the twenty-eighth annual report of the Massachusetts State Board of Health through the courtesy of the late Dr. Samuel W. Abbott. The figure for England from 1628 to 1642 is that given by Lexis ('92). The ratio for the United States was computed from 2,021,955 births 1,038,432 males and 983,523 females - the statistics for which were furnished by the health officers of the various states having reliable statistics of births.

\section{TABLE II.}

Nation

German Empire (1871-1880) . Switzerland

Austria

Italy

France

Belgium

Holland

Denmark .

England (modern times. Living births only)

England (1628-1642)

Sweden

Norway

Massachusetts (1876-1896) still births included

Massachusetts (1856-1875) living births only .

United States

Mean of all ratios
Number of males to 1000 females

1062

1063

1067

1071

1063

1058

1063

1058

1038

1068

1060

1061

1066

1055

1056

1060 
A considerable increase in the sexual ratio occurs when still births are included. The sexual ratio for the city of Chicago, based upon all births reported in the years 1898 to 1902 inclusive, $(141,233)$, is 1065 . During this period 4828 males and 3554 females were prematurely or still-born. If these premature and still-births are deducted from the total number reported, the number of males to 1000 females is 1035 . It becomes necessary, then, to decide whether or not still-births shall be counted. Stillbirths must be reported under penalty. Since the living children are the ones voluntarily reported, their record is not complete; but we may suppose that the parents are as apt to report a birth of one sex as of the other. The statistics of living births, therefore, in localities where birth registration is not compulsory, probably approach more nearly to the true ratio than the ratio based upon both still- and living births. If birth registration is compulsory, the ratio should be computed on a basis of all births reported. The ratio for Chicago computed on the basis of living births only is very nearly the same as the ratio for England. The ratio for Massachusetts, computed from living births only, is less than that based upon both living and still births. It is probable, therefore, that the incompleteness of the statistics is the most serious source of error.

The constancy of the sexual ratio.- An examination of the statistics shows a remarkable constancy of the sexual ratio in all parts of Europe and in the United States, for a period ranging from 1856 in Massachusetts, through 1871-1880 in the German Empire, to the year 1902 in Chicago. During these years and in the various countries, there were periods of war and peace, of famine and plenty, beside a great variety of racial and climatic conditions. Yet the greatest variation from the mean, exclusive of England, is only eleven in 1000 - a difference of one per cent.

In the same country for a period of years, the ratio is approximately constant. As an example, we may take the statistics for England (Table III) during the twelve years from 1888 to 1899 , inclusive. 
Table III.

(Taken from Sessional Papers of the House of Lords)

\begin{tabular}{|c|c|c|c|c|}
\hline Year & Total Births & Males & Females & $\begin{array}{c}\text { Males to } \\
1000 \text { Females }\end{array}$ \\
\hline 1899 & 928646 & 473172 & 455474 & 1039 \\
\hline 1898 & 923265 & 468920 & 454345 & 1032 \\
\hline 1897 & 921693 & 469180 & 452513 & 1037 \\
\hline 1896 & 915331 & 465660 & 449671 & 1035 \\
\hline 1895 & 922291 & 468886 & 453405 & 1034 \\
\hline 1894 & 890289 & 453016 & 437273 & 1036 \\
\hline 1893 & 914572 & 465711 & 448861 & 1037 \\
\hline 1892 & 897957 & 456622 & 441335 & $1034-5$ \\
\hline 1891 & 914157 & 465660 & 448497 & 1038 \\
\hline 1890 & 869937 & 442070 & 427867 & 1033 \\
\hline 1889 & 879868 & 447172 & 423696 & 1033 \\
\hline 1888 & 885944 & 451218 & 434726 & 1037 \\
\hline & $10,864,950$ & $5,527,287$ & $5,336,663$ & 1036 \\
\hline
\end{tabular}

It will be seen that the ratio for any one year does not differ by more than four in one thousand from the mean calculated from more than ten million births. As a further example, the sexual ratio in Massachusetts, based upon living births only, for the years 1856 to 1875 inclusive is 1059 . The ratio for the years 1876 to 1896 inclusive, based upon a considerably greater number of births, is 1053. The mean for the two periods is 1055. The sexual ratio for the period in which the Civil War occurred differed by approximately one half of one per cent from the later period of peace, and by less than one half of one per cent from the mean of the two periods. If external conditions exerted any effect upon the parents in such a way as to change the sex of the offspring, the change due to such influences was not greater than one in two hundred.

Social, political and material conditions in England during the years 1628 to 1642 were vastly different from those during the years 1888 to 1899 , but the difference between the sexual ratios for the two periods - 1068 to 1000 , and 1036 to 1000 respectively - is not greater than the difference between the ratios for the city 
of Chicago computed upon the living births only for a given period, and upon all births for the same period. It does not, therefore, appear necessary to assume with Strasburger that the sexual ratio for England has changed to any considerable extent in two hundred years.

The effect of a war upon the sexual ratio.- It has long been a current belief that more males were born in a period following a war than in a similar period of peace. Newcomb considers this statement unworthy of serious consideration. It may be said that, so far as the United States is concerned, such statements are based upon an insufficient number of births, and that the statistics are for the most part worthless. I have many letters from state health officers to the effect that there are now no reliable statistics. of births in their respective states.

The sexual ratio independent of external conditions.- In view of the remarkable constancy of the sexual ratio under diverse social, political and material conditions and for long periods of time in different races, it seems incredible that the determination of sex should be dependent upon external conditions.

If the sex of the offspring is independent of external conditions, what is the determining factor? Two general explanations are open. There is first the possibility that sex is determined by a series of accidents, as Newcomb suggests, and second, the possibility that sex is hereditary.

The possibility that sex is determined by a series of accidents.Newcomb likens the sex of a child to a particle floating on a stream of water. In the early part of its course the stream is single, but an obstacle divides it into two at the lower part. A particle entering the stream at the upper part may pass on either side of the obstacle, the exact course depending upon a multitude of accidental causes up to a certain point, after which its course on one side of the barrier or the other is fixed. So with an ovum. In its early development, there is the possibility of developing into either a male or a female, the sex depending upon a series of accidents.

Newcomb showed from statistics that the probability that twins will be of the same sex is .77, and the probability that they will be of opposite sexes is .23. It is impossible to tell from Newcomb's, 
tables whether duplicate twins were excluded, as they should have been, since but one ovum is involved. If duplicate twins had been excluded, the probability that ordinary twins would be of the same sex might have been even less than .77; for duplicate twins are invariably of the same sex.

Sex determined before the first cleavage of the ovum.- Let us now examine into the bearing of these considerations upon Newcomb's hypothesis. To continue his simile, two particles starting together will have a greater chance of remaining together and passing on the same side of the barrier than two particles somewhat removed from each other. Similarly, two ova developing together (in the same environment) will have a greater chance of producing offspring of the same sex than two ova developing at different times, but neither the two particles nor the two ova invariably follow the same course. If any series of accidents acting upon the ovum after fertilization is to determine the sex of the twins, it is incredible that it should always produce the same result in both. Since, however, duplicate twins are always of the same sex, this view becomes untenable, and we must limit the action of a series of accidents to the period preceding and possibly including fertilization. The conclusion that at or immediately after fertilization, the sex of the offspring is determined once for all seems inevitable. The effect upon the ovum of any series of accidents must cease before the first cleavage is accomplished.

Is sex determined by either parent alone?-Having concluded that the sex of the offspring is determined at or before the time of fertilization, we may inquire further whether the sex of the offspring may not be determined by the ovum alone, or by the spermatozoon alone. First, the ovum, may have the potentiality of developing into either a male or a female embryo. During maturation the chromatic material necessary for the development of an embryo of one sex is cast off in the polar bodies, and that necessary for an embryo of the other sex is retained. The spermatozoon thus plays a purely asexual rôle. This hypothesis postulates a qualitative reduction of the chromatin in maturation. According to another variety of this hypothesis the ovum assumes the asexual rôle, and the sex of the embryo is determined solely by the spermatozoon. Since all spermatozoa do not produce 
embryos of the same sex, there must have been, at some period in the development of the spermatozoon, a qualitative reduction of the chromosomes, those necessary for a male going into one spermatozoon, and those necessary for a female into another. If we accept this hypothesis, we must show why a constant and unequal proportion of all ova or of all spermatozoa have chromosomes, e. g. the accessory chromosome, which will produce an embryo of a certain sex. As an alternative hypothesis we may suppose that both ovum and spermatozoon play a sexual rôle, and that the sex of the embryo, in common with other characteristics, is determined by both sexual elements. This view, as I shall show subsequently, is the more probable.

If we cannot explain the cause of sex by postulating a series of accidents of unknown nature occurring after fertilization, can we explain it on the second possibility,- heredity? And if so, which of the two great laws of heredity are applicable to the case? The first question I shall answer in the affirmative, and proceed to the discussion of the second.

The application of Mendel's law.- On the basis of Mendel's law we must suppose that each ovum has equal chances of developing into a male or into a female embryo. Given two thousand ova, chosen at random, the chances are even that a thousand of them will develop into males and one thousand into females. We might reasonably expect also that in some groups we would find an excess of males, and in others an excess of females, but the mean of all groups would be 1000 each of males and females.

Punnett (:04b) in order to test Bateson's suggestion, attempted an enumeration of the sexes in Carcinus manas. He found an excess of females in groups of individuals of the same size, but this excess decreased in groups of younger individuals and there were indications of an approximately equal distribution of the sexes at the time of hatching. The exact proportion of the sexes at the time of hatching could not, however, be determined.

McIntosh ('04,) from a study of the Norway lobster, concluded that the young were hatched in about equal proportions of the sexes, but was not able to determine the exact proportion.

Taking the English statistics given in Table III as a basis, we may compute the probability that the actual distribution of males 
and females would be obtained by such a random choice. Instead of the theoretical distribution of 1000 males and 1000 females, the actual numbers of males and females in 2000 births are 1017.6 and 982.4 respectively, or, for convenience in calculation, 1018 males and 982 females. The probability that, in choosing at random, we should obtain such a distribution is .60984 $\times 10^{-920}$. The probability that in eleven such choices, we would always obtain the same distribution is infinitesimal. The probability that, in every case where the births are numerous enough to be representative of the actual conditions, we should always obtain practically the same distribution is practically zero. There is about the same probability that Mendel's law holds for all these cases.

A single concrete example taken from organic chemistry will serve to emphasize this point and perhaps to make this mathematical abstraction clearer. In the transformation of acetaldehyde to lactic acid by the addition of hydrocyanic acid, saponification and oxidation, each of two isomeric forms of lactic acid is, on the theory of probability, equally likely to be produced. The two forms differ in optical activity, one being dextro-rotatory and the other laevo-rotatory. Experimentally, it is found that the two forms are actually produced in exactly equal amounts, and the mixture of the two is optically inactive. A variation of from three to seven per cent from the theoretical yield would be fatal to the theory of probability. In general, in the synthesis of organic bodies in which two isomeric forms are possible and theoretically equally probable, the experimental results agree much more closely with the theory than do the statistical resuits of human births.

Neither ovum nor spermatozoon play asexual roles. - It is evident that these considerations apply also to the hypothesis that either the ovum or the spermatozoon play a purely asexual rôle. If we suppose that, in the qualitative reduction of the chromosomes, male and female chromosomes are equally likely to be extruded in the polar bodies, there is practically no probability at all that we would obtain the actual distribution of males and females. If the hypothesis is correct, there must be some definite regulative mechanism of unknown nature which determines the extrusion of the chromosomes. It is incumbent upon those 
who maintain the truth of such a hypothesis to explain the nature of this unknown mechanism.

In the case of the accessory chromosome (McClung, :02), the statement is made that it occurs in one half of the spermatozoa of Orthoptera and Hemiptera. If we are to suppose that the accessory chromosome acts as a sex determinant, and that sex characters are to be treated as if they were Mendelian alternates (Wilson, '07), we should find a sexual ratio equal to unity or differing from unity by an extremely small per cent. We cannot, however, account for the determination of sex in the human subject on any basis of an equal division of spermatozoa into male and female producing sperms, unless we suppose, as Wilson concedes for the sake of argument, that sex may be modified by external conditions. The statistical evidence is strongly against this alternative. If it can be shown that the accessory chromosome occurs in the spermatozoa of a species in the same proportion as the sex to which it gives rise occurs in the young of that species, the statistical evidence in its favor will be increased. At present, there is no such evidence in its favor, as we do not know the exact sexual ratio of the species in which the accessory chromosome has been observed.

The strongest evidence known to the author in favor of the Mendelian theory of dominance in the determination of sex is that cited by Harper (:07) in regard to plants. That the stamens should develop and the pistil be suppressed in the fungus-infected female plants of the campion is strongly suggestive of the recessiveness of the stamens under ordinary conditions.

The application of Galton's law.- To explain the remarkable constancy of the sexual ratio by Galton's law, we have only to assume that sex, in common with other physical characteristics, is inherited equally from the paternal and maternal ancestry; and to explain the preponderance of males in the present generation, we assume that in this ancestry for five or six generations back, there has been a preponderance of males. In this we are justified since there is direct statistical evidence that, for more than two hundred years, there has been an excess of male births in England. Accepting the statistics as being reasonably accurate, the accordance with Galton's law of ancestral inheritance is much. closer than with Mendel's law. 


\section{The Biological Significance of the Sexual Ratio.}

Rauber, apparently taking the view that an excess of females is the normal condition, explains the present preponderance of male births in man by supposing that those tribes or families which, in primitive times, had the greatest proportion of males would possess a certain advantage in warfare and thus be enabled to overpower those in which there was a larger proportion of females. The male preponderance, once established, would be perpetuated by heredity. This ingenious explanation, does not, however, account for the excess of females among the domestic animals. What the sexual ratio was in primitive man we have no means of knowing. Neither do we know what the sexual ratio was in horses and sheep before they were domesticated. One would expect that the sexual ratio in wild animals would depend somewhat upon the mating and breeding habits of a species. In those species of birds, in which one male mates with one female for a season or for life, we might expect that the sexual ratio would be nearly unity, the excess of one sex or the other depending on which one was exposed to the greater dangers and had the less chance of growing to maturity. In herds of wild horses, cattle and bison, there are many females to one male. All but the strongest males are killed off by the others and the number of adult males is thus kept down to the needs of the herd. Those individuals which are most likely to produce males are not always the ones likely to reproduce. In the dairy industry, females are of more value than males, and it is possible, in fact more than probable, that man has unconsciously, by selection in breeding, increased the proportion of female births.

No one sexual ratio may be taken as the standard.- If sex is hereditary, we might reasonably expect that the relative numbers of male and female births in any species would be those which, after deducting the early deaths, would confer upon the species at the period of sexual maturity of its individuals the greatest advantage in the struggle for existence so far as the production of young is concerned. This would mean that the species would enjoy the maximum reproductive power, and this condition would. be fulfilled when there were no superfluous, sexually mature males or females. 
Let us suppose that a species possesses the maximum reproductive power when there are $x$ males to $n$ females, the relative magnitudes of $x$ and $n$ depending upon the breeding habits of the species. Let us suppose also that $a$ males and $b$ females die before reaching sexual maturity. The number of males born will therefore be $a+x$, and the number of females $b+n$. The sexual ratio will be $\frac{a+x}{b+n}$, or $\frac{a+x}{b+n} \times 1000$ if we wish to express the number of male births to 1000 female births.

In a monogamous species, such as the American robin, the reproductive power of the species would be at a maximum when there were equal numbers of sexually mature males and females. If the males are more likely to be killed off than the females, $a$ would be greater than $b$, and the sexual ratio would be greater than unity. Surplus males or females would die off without reproducing. In a polygamous species, such as the ox, it is not necessary that there be equal numbers of sexually mature males and females to give the species its maximum reproductive power, and $a+x$ might well be less than $b+n$. The sexual ratio would in this instance be less than unity. The relative proportions of the sexes in any species may, therefore, be looked upon as one of the physiological adaptations of the species, determined by the conditions of its. existence.

\section{The Experimental Point of Attack.}

If sex is inherited according to Galton's law it should be possible, by suitable selection of the parents, to establish a strain of animals. or plants in which males or females occur with any desired degree of frequency compatible with perpetuation of the species. The practical benefits of the favorable results of such an experiment to the dairy and grazing interests of the country would be difficult to estimate. Castle has recently published some experiments on the effects of inbreeding, cross-breeding, and selection upon the fertility of flies (Drosophila) in which he found no marked change in the sexual ratio. Other experiments are now in progress.

There is, however, a second point of attack which is more distinctly within the province of the physiologist. As previously pointed out, it is difficult to imagine why ordinary twins should 
often be of different sexes while duplicate twins are invariably of the same sex if nutritive or any other conditions outside of the ovum itself are responsible for the sex of the offspring. It is perhaps conceivable that, in the case of ordinary twins, the placental circulation may be more highly developed, and the nutrition consequently better, for one twin than for the other, or that some peculiar local characteristic of the uterine wall may affect one twin more than the other. The probability of any such dissimilarity of conditions in the case of duplicate twins, where the same placenta supplies both with nutriment, and any local peculiarity of the uterine wall affects them equally, is very small. It must therefore be admitted that ordinary twins may be subjected to more diverse conditions during development than duplicate twins, and it is conceivable that the latter might sometimes be of opposite sexes if we could vary the conditions during development. This would manifestly be a matter of great difficulty in mammals, but a simpler method of attack is open.

Roux ('85) and others have shown that the individual blastomeres of a frog's egg will, when separated from the others, develop into complete embryos. Such embryos are presumably comparable in all respects to duplicate twins, and if by any means we might cause two blastomeres from the same ovum of any animal normally reproducing sexually to develop into embryos of opposite sexes, we would have a demonstration that sex was not determined at the time of fertilization of the egg. Failure to produce from the same egg two embryos of opposite sex would be evidence that we have, at present, no known means of changing the sex of the embryo after fertilization of the egg. It is incumbent upon those who maintain that sex is determined by the environment to show that two embryos of opposite sexes can be produced from the same ovum. The experimental solution of the problem of the causes which influence the sex of the offspring, as well as the significance of sex itself, is to be sought in the simple cell whose environment can be varied in a known way and to a known extent. It is obvious, also, that the problem of sex determination is but a particular phase of the much wider problem of the extent to which the ovum may be modified by a change in the external environment. Furthermore, if we acquire experimental data on the deter- 
mination of sex, we will at the same time acquire experimental data on the question of a period of sexual indifference in the development of the individual. If sex is determined, as appears probable from the statistical data, at the time of fertilization, it is difficult to conceive of a period of real sexual indifference in the history of the individual. But if we can influence the sex of an individual after fertilization of the ovum, we will at the same time demonstrate a period of sexual indifference in development.

The bearing of artificial parthenogenesis on the problem of sex. - In a personal communication to the writer, Dr. Woelfel has suggested that if, by any means other than fertilization by a spermatozoon, we are able to cause an ovum of an animal which normally reproduces bisexually to develop to sexual maturity, we will have a demonstration that one parent plays a purely asexual rôle in the production of sex. This conclusion, however, does not follow necessarily. Moreover no individual arising by artificial parthenogenesis has as yet grown to sexual maturity. Whether this failure of normal development is due to improper nutrition of the young or to a lack of some essential detail in fertilization cannot, perhaps, be stated at present. One is inclined to regard the production of a sexually mature individual, which may in its turn reproduce, and the transmission of certain hereditary characteristics to the offspring as two essential details of fertilization. Until these phenomena have been imitated by artificial means, one is loath to believe that normal fertilization is imitated in all essential details by artificial parthenogenesis (Loeb :06). The study to artificial parthenogenesis may have an important bearing upon the determination of sex, but the true significance of the work already done is not apparent.

\section{Summary and Conclusions.}

The statistical study of the distribution of sex in man shows that there is a slight but constant excess of male births. The greater mortality of the males leads to a preponderance of females in old age.

There are certain unavoidable errors in the statistics, the two most serious being (1) incompleteness, and (2) disregard of dupli- 
cate twins. It is not probable, however, that these errors are in such a direction as would change the sexual proportion if we could get absolutely correct statistics.

The sexual ratio is remarkably constant in widely different localities and at widely different times; in a given locality the ratio is not altered by the varying social and material conditions of the parents, as indicated by statistics.

The study of duplicate twins shows that if sex is determined by a series of accidental causes, such causes cannot be operative after the fertilization and first segmentation of the ovum.

The logical conclusion from the statistical data is that sex is hereditary. Mendel's law does not apply. The constancy of the sexual ratio for more than two hundred years may best be explained by supposing that sex follows Galton's law of ancestral inheritance.

If sex is hereditary, we may explain the significance of the sexual ratio on the basis of natural selection by supposing that the proportion of the sexes in any species is such as will give that species the maximum reproductive power at the time of sexual maturity of its individual members. The sexual ratio may be expected to vary for different species, depending upon the mating and breeding habits of any particular species. The sexual proportion may be considered as one of the physiological adaptations of a species.

The conclusions drawn from statistical data should be tested experimentally. There are two experimental points of attack: (1) Breeding experiments to determine whether the sexual proportion can be altered by selection. (2) Experiments on the separate blastomeres from one ovum to determine whether two embryos of different sexes can be reared from the same egg, and whether there is a period of sexual indifference in the development of an individual.

Hull Physiological Laboratory

ChicAGo 


\section{BIBLIOGRAPHY.}

Only a partial bibliography is given here. Cuénot and Düsing ('84). give all the literature for animals up to 1899. Strasburger and Gregory give the botanical literature. A less complete review is given by Loeb. (:06).

Bateson, W. and Saunders, E. R.

:02. Experimental studies in the physiology of heredity. Reports to the Evolution Committee, No. 1, London.

Born, G.

'81. Experimentelle Untersuchungen über die Entstehung der Geschlechtsunterschiede. Breslauer ärtzliche Zeitschrift, 3, p. 25. Castle, W. E.

:03. The Heredity of Sex. Bull. Mus. Comp. Zool., 40, pp. 189-218. Castle, W. E., Carpenter, F. W., Clark, A. H., Mast, S. O., and BarRows, W. M.

:06. The effects of Inbreeding, Cross-breeding and Selection upon the Fertility and Variability of Drosophila. Proc. Amer. Acad. Arts and Sciences, 41, pp. 729-786.

CuÉnot, L.

'99. Sur la determination du sexe chez les animaux. Bull. scientif. de la France et de la Belgique, 32, pp. 462-535.

DüsIng, C.

'84. Die Regulierung des Geschlechtsverhältnisses bei der Vermehrung: der Menschen, Thieren und Pflanzen. Jenaische Zeitsch. f. Naturwissenschaft. 17, p. 593.

DüsIng, C.

'85. Der Experimentelle Prüfung der Theorie von der Regulierung. der Geschlechtsverhältnisses. Idem, 19, supp. Heft 2, p. 108.

Geddes, Patrick, and Thompson, J. Arthur.

:01. The Evolution of Sex, Chapter IV, 2d. ed. London.

GREGory, R. P.

:04. Some observations on the determination of sex in plants. Proc. Cambridge Phil. Soc., 12, pp. 430-440.

Griesheim, A.

'81. Ueber die Zahlenverhältnisse der Geschlechter bei Rana fusca. Arch. f. d. ges. Physiol., 26, p. 237.

HaRper, R. V.

:07. Sex Determining Factors in Plants. Science, N. S. 25, pp. 379382.

IssaKo ITISCH, A.

:06. Geschlechtsbestimmende Ursachen bei den Daphniden. Arch. f. mikr. Anat., 69, p. 223. 
LeXIS.

'92. Geschlechtsverhältniss der Geborenen und der Gestorbenen. Handwörterbuch der Staatswissenschaften, 3, p. 816: new edition 1900, 4, p. 177, cited by Strasburger (:00).

LowB, J.

:06. The dynamics of living matter. N. Y. and London. Chapters IX and $\mathrm{X}$.

McClung, C. E.

:02. The accessory chromosome - sex determinant? Biol. Bull. 3 , pp. $43-84$.

von Malsen, $\mathrm{H}$.

:06. Geschlechtsbestimmende Einflüsse und Eibildung bei Dinophilus apatris. Arch. f. mikr. Anat. 69, p. 63.

McIntosh, D. C.

:04. On the variation in the number and arrangement of the male genital apertures and on the proportion of the sexes in the Norway lobster. Proc. Cambridge Philos. Soc., 12, pp. 441-444.

Newcomb, S.

:04. A Statistical Inquiry into the Probability of Causes of Sex in Human Offspring. Carnegie Institution, Publication No. 11, pp. 1-34.

PFLÜGER, E.

'81. Einige Beobachtungen zur Frage über die das geschlechtsbestimmenden Ursachen. Arch. f. d. ges. Physiol. 26, p. 243.

'82a. Hat die Concentration des Samens einer Einfluss auf das Geschlecht? Idem, 29, p. 1. (Has no effect.)

'82b. Ueber die das geschlechtsbestimmende Ursachen und die geschlechtsverhältnisse der Frosche. Idem, 29, p. 13.

Punnett, R. C.

:04a. On nutrition and sex determination in man. Proc. Cambridge Phil. Soc., 12, pp. 262-276.

:04b. Note on the proportion of the sexes in Carcinus mænas, Idem, pp. 293-296.

RAUBER, A.

:00. Der Ueberschuss an Knabengeburten und seine biologische Bedeutung. Leipzig. (Abstract by R. F. Fruchs in Biol. Centralbl., 21, p. 833, 1901).

Rowntree, B. S.

:02. Poverty, a study of town life. Second edition. Roux, W.

'85. Ueber die Bestimmung der Hauptrichtungen des Frosch-embryos im Ei, und über die erste Teilung des Froscheies. Breslauer ärtzliche Zeitsch. [The literature is given by Wilson (1900)].

Strasburger, E.

:00. Versuche mit diöcischen Pflanzen in Rücksicht auf Geschlechts- 
verteilung; Biol. Centralbl., 20, pp. 657-65, 689-98, 721-31, $753-85$.

WELDON, W. F. R.

:01-:02. Mendel's Laws of Alternative Inheritance in Peas. Biometrika, 1, pp. 228-254.

WILDER, H. $\bar{H}$.

:04. Duplicate Twins and Double Monsters. Amer. Journ. of Anat., 3, p. 387.

WILSON, E. B.

:00. The Cell in Development and Inheritance. 2nd ed. New York, p. 408 et seq.

:07. Sex determination in relation to fertilization and parthenogenesis. Science, N. S. 25, pp. 376-379.

Yung, EMILE.

'83. Contributions à l'histoire de l'influence des milieu physicochimiques sur les êtres vivants. Arch. de Zool. experimental, $2 \mathrm{e}$ serie, 1, p. 31.

'85. Influence des variations du milieu physico-chimiques sur le développement des animaux. Arch. des Sciences Phys. et Naturelles, 14 , p. 502 . 